\title{
IMPLICIT DIFFERENCE FUNCTIONAL INEQUALITIES AND APPLICATIONS
}

\author{
Z. KAMONT AND K. KROPIELNICKA
}

\begin{abstract}
We give a theorem on implicit difference functional inequalities of the Volterra type for functions of several variables. We apply this general result in the investigation of the stability of implicit difference functional equations with initial boundary conditions.

Classical solutions of parabolic functional differential equations are approximated in the paper by solutions of suitable implicit difference schemes. The proofs of the convergence of difference methods are based on comparison technique and results on difference functional inequalities are used. Numerical examples are presented.
\end{abstract}

Mathematics subject classification (2000): 35R10, 65M12.

Key words and phrases: Difference inequalities, initial boundary value problems, stability and convergence, implicit difference methods.

\section{REFERENCES}

[1] A. BYCHOWSKA, Quasilinearization methods for nonlinear parabolic equations with functional dependence, Georgian Math. J., 9 (2002), 431-448.

[2] S. BRZYCHCZY, Existence of solutions for nonlinear systems of differential-functional equations of parabolic type in an arbitrary domain, Ann. Polon. Math., 47 (1987), 309-317.

[3] W. JÄGER, L. SIMON, On a system of quasilinear parabolic functional differential equations, Acta Math. Hungar., 112 (2006), 39-55.

[4] Z. KAMOnT, Hyperbolic Functional Differential Inequalities and Applications, Kluwer Acad. Publ., Dordrecht (1999).

[5] Z. KAMONT, H. LESZCZYŃSKI, Stability of difference equations generated by parabolic differential functional problems, Rend. Mat., 16 (7) (1996), 265-287.

[6] W. KoHL, On a class of parabolic integro - differential equations, Zeit. Anal. Anwend., 19 (2000), 159-201.

[7] K. KRopielnicKa, Implicit difference methods for parabolic functional differential equations, Func. Diff. Equat., 13 (2006), 483-510.

[8] K. KROPIELNICKA, Implicit difference methods for nonlinear parabolic differential functional systems, Demonstratio Math., 39 (2006), 711-728.

[9] M. MALEC, M. RosaTI, Weak monotonicity for nonlinear systems of functional - finite difference inequalities of parabolic type, Rend. Mat., 3 (7) (1983), 157-170.

[10] M. MALEC, A. SCHIAFFINO, Méthode aux différences finies pour une équation non-linéaire differentielle fonctionelle du type parabolique avec une condition initiale de Cauchy, Boll. Un. Mat. Ital. B (7), (1987), 99-109.

[11] R. ReDhefFer, W. Walter, Comparison theorems for parabolic functional inequalities, Pacific. J. Math., 85 (1979), 447-470.

[12] R. REDHEFFER, W. WALTER, Stability of the null solution of parabolic functional inequalities, Trans. Amer. Math. Soc., 262 (1980), 285-302.

[13] R. REDLINGER, Existence theorems for semilinear parabolic systems with functionals, Nonlinear Anal., 8 (1984), 667-682. 
[14] A. L. SKUBACHEVSKII, Second-order parabolic differential difference equations, Dokl. Akad. Nauk, 379 (2001), 595-698.

[15] J. SZARSKI, Strong maximum principle for non - linear parabolic differential - functional inequalities, Ann. Polon. Math., 29 (1974), 207- 214.

[16] J. SZARSKI, Uniqueness of the solution to a mixed problem for parabolic functional - differential equations in arbitrary domains, Bull. Acad. Polon. Sci. Sŕ. Sci. Math. Astronom. Phys., 24 (1976), $841-849$.

[17] W. VoIGT, Two-sided estimations for nonlinear parabolic systems with functionals, Z. Anal. Anwendungen, 6 (1987), 439-447.

[18] W. VoIGT, Finite difference schemes for parabolic problems with first and mixed second derivatives, Zeit. Angew. Math. Mech., 68 (1988), 281-288. 